\title{
Summer and winter diet of four carnivorous copepod species around South Georgia
}

\author{
Vidar Øresland ${ }^{1}$, Peter Ward ${ }^{2}$ \\ ${ }^{1}$ Department of Zoology, Stockholm University, S-106 91 Stockholm, Sweden \\ ${ }^{2}$ British Antarctic Survey, Natural Environment Research Council, High Cross, Madingley Road, Cambridge CB3 0ET, \\ United Kingdom
}

\begin{abstract}
The natural diets of adult female Euchaeta antarctica, E. farrani, E. rasa and E. biloba, as well as male and female copepod stage $V E$. antarctica, were compared through gut content analyses. Copepods of variable size dominated the diet of all predators during both seasons ( 46 to $99 \%$ of all food items). Mean number of prey per predator $(0.9$ to 8.6$)$, as well as the distribution of predators with different numbers of prey in the gut, indicated no general decrease in feeding by Euchaeta spp. during the Antarctic winter. Diet of adults was broad and overlapping in both seasons. During summer, copepod nauplii and the small copepods Drepanopus forcipatus and Oithona spp. dominated the diet of CV E. antarctica in the upper $200 \mathrm{~m}$. Nauplii were hardly taken at all by adult E. antarctica in that depth interval. During winter $D$. forcipatus dominated the diets of both $C V$ and adult $E$. antarctica, and of $E$. biloba. Among CV female E. antarctica $13 \%$ of individuals took $44 \%$ of all food items during winter. This emphasises the patchy nature of feeding in the sea and indicates the importance of adequate sampling scales and sample size in feeding studies.
\end{abstract}

\section{INTRODUCTION}

The general structure of Southern Ocean food webs is becoming increasingly better known (e.g. Hopkins 1985, 1987, Hopkins \& Torres 1989, Hopkins et al. 1993). However, detailed information is still lacking, especially on food web dynamics and seasonal variation. Different feeding strategies may develop among different zooplankton species during winter, potentially from increased carnivory to diapause, in response to the strong reduction of primary production. Carnivorous feeding may be a widespread and important factor in the regulation of prey populations during the long winter period (Øresland 1991, Hopkins et al. 1993). Information on the carnivorous feeding of important macrozooplankton groups, e.g. chaetognaths, euphausiids, amphipods, and predatory copepod families like the Euchaetidae, will therefore contribute to our understanding of Southern Ocean ecosystem dynamics.

This study focuses on the Euchaetidae which is a widespread, mainly carnivorous, calanoid copepod family containing over 90 species of which 14 have been recorded around South Georgia (Ward \& Wood 1988). The feeding of the Euchaetidae in the Southern Ocean has mainly been studied in the summer period. Øresland (1991) studied the natural feeding of Euchaeta antarctica during the summer in Gerlache Strait, Antarctic Peninsula, and in the north Weddell Sea. Yen (1991) carried out laboratory feeding studies on the same species (also from Gerlache Strait). Some dietary data is also given in the papers by Hopkins \& co-authors cited above. In this study the natural summer and winter diet in the 4 most abundant Euchaeta species collected around South Georgia, E. antarctica, E. biloba, E. rasa and E. farrani, were compared through gut content analyses.

\section{METHODS}

Material was taken from zooplankton samples collected during 2 surveys carried out around South Georgia $\left(54^{\circ} \mathrm{S}, 38^{\prime} \mathrm{W}\right)$ during November-December 
Table 1. Euchaeta spp. Prosome lengths ( $\mathrm{mm}$ ) of 4 species in different seasons around South Georgia, and the total number of samples and the total sampled depth interval. $95 \%=95 \%$ confidence interval for mean length

\begin{tabular}{|c|c|c|c|c|c|c|c|}
\hline $\begin{array}{l}\text { Season/ } \\
\text { Species }\end{array}$ & $\mathrm{n}$ & Mean & $95 \%$ & Min. & Max. & Samples & $\begin{array}{l}\text { Depth interval } \\
(\mathrm{m})\end{array}$ \\
\hline \multicolumn{8}{|l|}{ Summer } \\
\hline E. antarctica VI female & 121 & 6.7 & 0.06 & 6 & 7.8 & 19 & $0-230$ \\
\hline E. biloba VI female & 116 & 4.1 & 0.02 & 3.8 & 4.4 & 11 & $0-2300$ \\
\hline E. rasa VI female & 120 & 4.4 & 0.03 & 4 & 4.8 & 4 & $250-1740$ \\
\hline E. farrani VI female & 123 & 7.6 & 0.04 & 7.2 & 8 & 10 & $240-2125$ \\
\hline E. antarctica $V$ female & 59 & 5.3 & 0.07 & 4.4 & 5.8 & 4 & $10-200$ \\
\hline E. antarctica $V$ male & 59 & 4.9 & 0.04 & 4.5 & 5.2 & 4 & $10-200$ \\
\hline \multicolumn{8}{|l|}{ Winter } \\
\hline E. antarctica VI female & 299 & 7.2 & 0.04 & 6.1 & 7.9 & 3 & $0-250$ \\
\hline E. biloba VI female & 120 & 4.2 & 0.03 & 3.6 & 4.5 & 7 & $240-510$ \\
\hline E. rasa VI female & 120 & 4.4 & 0.03 & 4.1 & 4.7 & 4 & $490-1005$ \\
\hline E. farrani Vl female & 96 & 7.6 & 0.04 & 6.9 & 8 & 10 & $255-1020$ \\
\hline E. antarctica V female & 60 & 5.1 & 0.06 & 4.5 & 5.5 & 5 & $15-495$ \\
\hline E. antarctica $V$ male & 60 & 4.9 & 0.05 & 4.6 & 5.5 & 5 & $15-495$ \\
\hline
\end{tabular}

1981 (summer) and July-August 1983 (winter). The samples were taken within a grid of stations that covered both the shelf and the deep water areas around South Georgia. See Ward \& Wood (1988) for full details of grid and sampling procedures. The grid comprised a series of 9 transects each $180 \mathrm{n}$ miles long and $30 \mathrm{n}$ miles apart with stations spaced along them at 30 nautical mile intervals. The samples were collected with a Rectangular Midwater Trawl (RMT1), with a mouth area of $1 \mathrm{~m}^{2}$ and a mesh size of $330 \mu \mathrm{m}$ (Roe \& Shale 1979). Table 1 shows the total sampled depth interval of the chosen samples. The shallow and deep hauls (single oblique) were of approximately $30 \mathrm{~min}$ to maximum $5 \mathrm{~h}$ duration, respectively. Zooplankton samples were preserved in $4 \%$ neutralised formaldehyde.

We wanted to compare diet between adult females of Euchaeta antarctica, E. biloba, E. rasa and E. farrani, as well as male and female copepod stage $\mathrm{V}$ E. antarctica. Adult male Euchaetiids have reduced mouth parts and do not feed. We wished to analyse approximately the same number of specimens of each species. Table 1 shows the number of specimens and the number of samples analysed. E. antarctica winter samples were analysed first. After 90 specimens had been analysed the proportions of large and small copepods found in the guts remained almost constant. Analysis of additional groups of 30 Euchaeta specimens changed the proportions by less than $5 \%$. Gut content analyses are time consuming, therefore the number of specimens analysed was reduced to approximately 120 specimens per season for each species and stage in the remaining analyses. All 96
E. farrani found during winter were analysed and this number set the lower limit of specimens analysed within a species.

Stage CV and adult Euchaeta antarctica were taken both at shelf and deep water stations. CVs were abundant only in the upper $250 \mathrm{~m}$. Therefore, both stages were taken in the upper water layer, in order to compare their diet. Only one of the CV E. antarctica winter samples was deeper than $280 \mathrm{~m}$ (see Table 1). The sampling depths of E. biloba, E. rasa and E. farrani encompassed their main centres of distribution (see Ward \& Wood 1988).

All euchaetiids were identified using Park (1978). The prosome length was measured to the nearest $0.1 \mathrm{~mm}$ under a stereomicroscope, using an eyepiece micrometer. The complete gut of the copepods was then dissected, using a microscalpel and tungsten needles following Øresland (1991). Analysis of gut contents was inferred from identification of prey mandibles or other identifiable prey parts observed through an inverted microscope. The part of the gut found inside the urosome was not analysed.

The prey categories are given in Table 2 . The summary prey category 'all large copepods' included all identified and unidentified large copepods with a mandible width $\geq 0.07 \mathrm{~mm}(\geq 0.06 \mathrm{~mm}$ for Metridia spp.) and comprised stages CIII of Euchaeta spp., CIII to CVI of Calanoides acutus, Calanus spp. and Metridia spp., and CV to CVI of Drepanopus forcipatus. The summary category 'all small copepods' includes all other copepods. When no mandibles were found the size (large or small) of the copepod prey was estimated from exoskeleton remains. 
Table 2. Percentage distribution of prey within 4 Euchaeta species around South Georgia. The summary category 'all large cop.' includes all copepods with a mandible width $\geq 0.07 \mathrm{~mm}$. 'All small cop.' includes all other copepodids. The relation between mandible widths to copepodite stage is given in the text. E. ant. = E. antarctica; E. bil. = E. biloba; E. far. = E. farrani

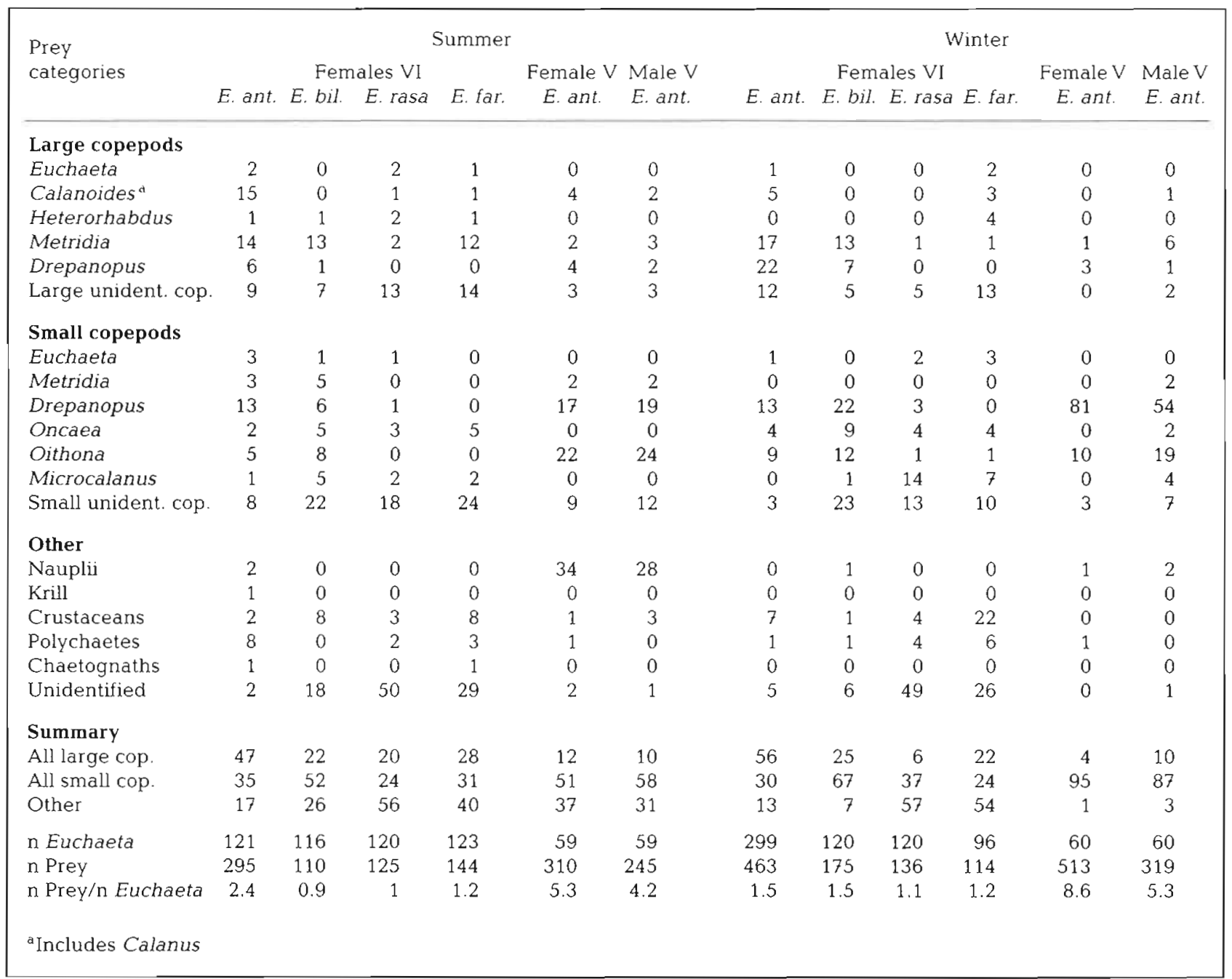

\section{RESULTS}

\section{Diet}

Predator size and developmental stage may be important factors affecting prey preference. Table 1 shows that female Euchaeta antarctica and E. farrani were much larger than E. biloba and E. rasa. There were little or no significant seasonal differences in species mean length with the exception of adult female E. antarctica.

The data in Table 2 show that copepods were the predominant prey of all species, comprising at least 43 to $99 \%$ of all prey items. These are conservative estimates since it is possible that most crustaceans in the guts were copepods. Often the crustacean remains appeared similar in size and general morphology to a copepod exoskeleton, although mandible remains were not found. All crustacean remains found in Euchaeta farrani during winter appeared to originate from relatively large prey (the size of an adult Calanus or bigger).

Unidentified objects were often found close to the urosome. Some of these objects were pellet-like, between 90 and $250 \mu \mathrm{m}$ long, and with 2 to 4 dark spots inside. They occurred in Euchaeta rasa $(6$ and $27 \%$ of all food items during summer and winter, respectively) and in E. farrani during winter (11\% of all food items). SEM observations failed to disclose their identity.

The diet, in terms of prey composition and prey size, of adult Euchaeta was broad and overlapping between species. Neither were there fundamental seasonal 
changes in diet. The larger species, E. farrani and $E$. antarctica, contained more large prey (large crustaceans in E. farrani included) than the smaller species E. rasa and E. biloba. Compared to adults, CV E. antarctica had a less diverse diet in both seasons. Copepod nauplii, small Drepanopus forcipatus and Oithona spp. were predominant in the diet of CVs during summer and small $D$. forcipatus dominated totally during winter. It is notable that adult E. antarctica took almost no nauplii although adults were sampled from the same depth interval as the CVs.

\section{Prey abundance in guts}

Fig. 1 shows that most adult females of Euchaeta biloba, E. farrani and E. rasa contained 1 or 2 prey items, while in E. antarctica up to 6 prey items were

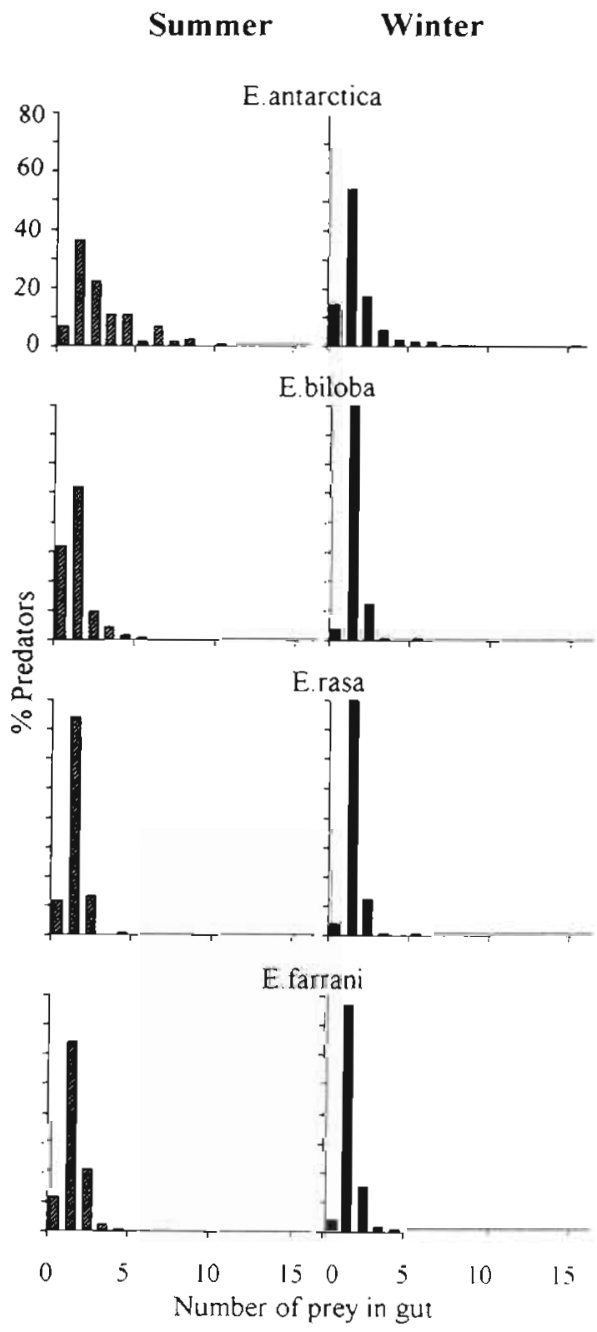

Fig. 1 Euchaeta spp. Percentage distributions of adult females with different numbers of prey items in the gut. Number of specimens analysed is given in Table 2 relatively common. In sharp contrast to the adults, CV E. antarctica contained more individuals with many prey items (Fig. 2). This is also reflected in the mean number of prey per predator given in the summary in Table 2 .

The percentage distributions of predators with different numbers of prey in their guts are not normally distributed. In many cases, relatively few predators took a large portion of all prey items. During summer and winter, the $5 \%$ of adult females and stage $\mathrm{V}$ Euchaeta antarctica containing most prey took 16 to $25 \%$ of all food items. Even in E. biloba the $5 \%$ with most prey items took a large portion of all prey $(23 \%$ in winter and $22 \%$ in summer. In E. rasa and E. farrani, however, these proportions decreased to below $13 \%$. During winter $13 \%$ of the CV female E. antarctica contained between 24 and 37 prey items (of which $87 \%$ were Drepanopus). This accounted for up to $44 \%$ of all prey items taken. Similar high values (minimum $36 \%$ ) were found for all CVs and adult E. antarctica as well as for E. biloba in both seasons. The percentage empty individuals ranged from $4 \%$ in E. rasa and E. farrani in winter, to $32 \%$ in E. biloba in summer.

\section{DISCUSSION}

\section{Methods}

In order to obtain sufficient specimens for this study it was necessary to analyse samples from several stations during both cruises. Accordingly, differences in sampling depth, sample size, diet and numbers of prey taken, etc., will potentially bias our data. Interpretations must therefore be limited to the most clearcut situations. No obvious indication of diel feeding was apparent when the mean number of prey per predator and percentage empty individuals were plotted against sampling time. However, we cannot omit the possibility of minor diel changes in feeding although Øresland (1991) found no indication of diel feeding behaviour in Euchaeta antarctica during summer.

In this study cod-end feeding is not regarded as a source of error, as no fresh undigested prey were found in any of the Euchaeta examined. The number of prey recovered from individuals should be considered as conservative estimates of their natural occurrence in the gut, due to digestion taking place while the predators were in the net $(30 \mathrm{~min}$ in shallow hauls to maximum $5 \mathrm{~h}$ in the deeper hauls). In addition, incomplete mastication of prey and losses of gut content due to hauling and handling would, if occurring, further reduce gut contents and bias feeding estimates. 
Summer Winter

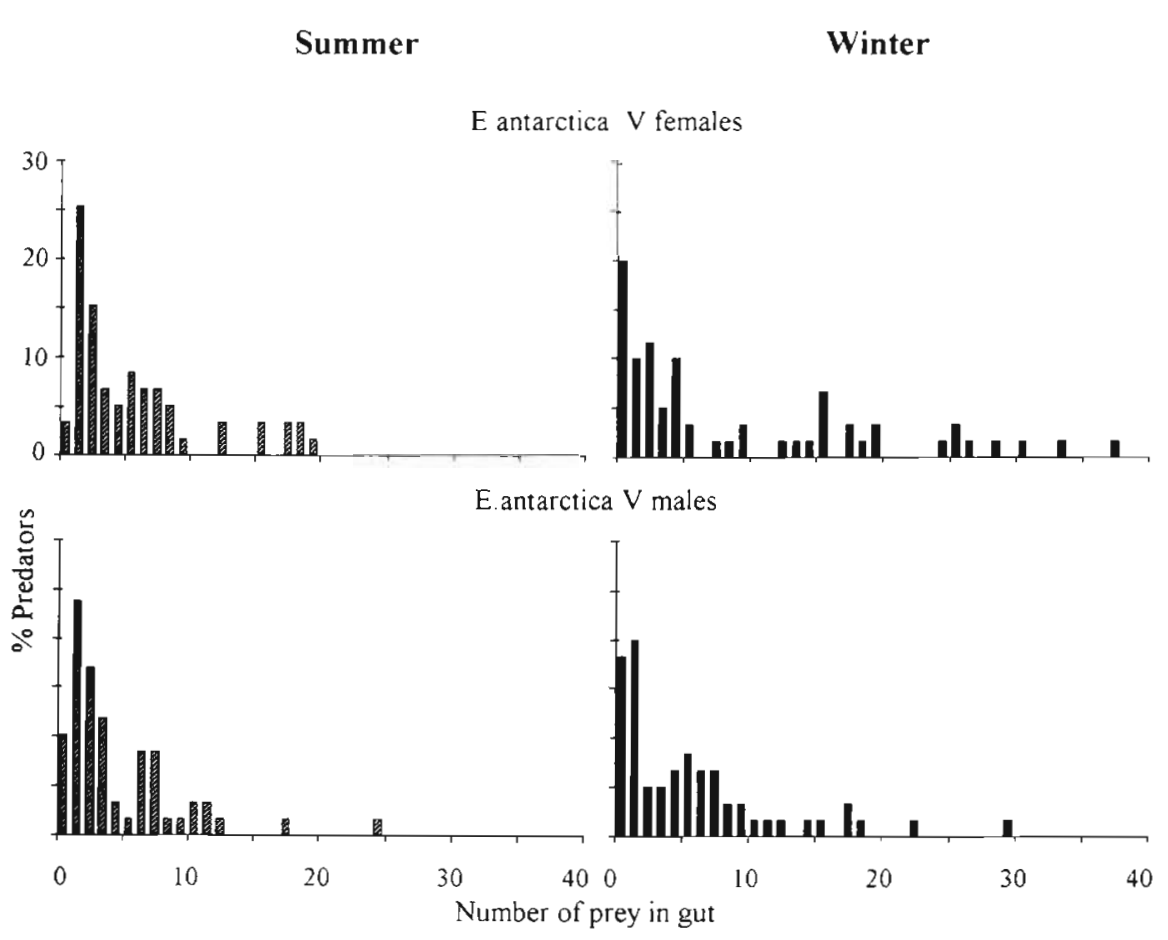

Fig. 2. Euchaeta antarctica. Percentage distributions of females and males at stage $\mathrm{CV}$ with different numbers of prey items in the gut. Number of specimens analysed is given in Table 2

\section{Diet}

Although copepods formed the major source of prey for all species of Euchaeta, other taxa such as polychaetes (mainly Pelagobia longicirrata) may, due to their size, contribute significantly to the diet although their numerical contribution was relatively small. $P$. Iongicirrata has also been found in chaetognaths, amphipods and Euchaeta in other areas (Hopkins 1985. 1987, Hopkins \& Torres 1989, Øresland 1990, 1991).

During winter Drepanopus forcipatus appeared to be a key prey species for CV Euchaeta antarctica. It also forms a major part of the diet of larval fish around South Georgia (North \& Ward 1990). D. forcipatus occurs commonly over the shelf and is reported to make a significant contribution to total zooplankton biomass in adjoining fjords (Ward 1989). D. forcipatus was, together with Metridia spp., important also in the diet of adult E. antarctica and E. biloba during both seasons but especially during winter. During summer Calanoides acutus may, due to their large size, make up an important part of the food intake of adult $E$. antarctica. It should be noted, however, that during winter the majority of Calanoides acutus may have been below the sampling depth of E. antarctica (Atkinson \& Ward 1988). The importance of large copepods in the diet of adult $E$. antarctica during summer was also discussed in Øresland (1991).

Since the copepod nauplii taken during summer were almost certainly restricted to the upper part of the water column it is remarkable that they were taken almost exclusively by CV Euchaeta antarctica but not by adults. It should be noted that adult $E$. antarctica was able to take prey as small as Oncaea spp. and Microcalanus spp. The other Euchaeta species were sampled from below the principal depth range of the nauplii at this time of year.

Yen (1991) found (based on laboratory experiments) that the size of the preferred copepod prey (prosome length $=1.2 \mathrm{~mm}$ ) was $65 \%$ of the length of the 2 nd basipodal segment of the maxilliped of adult female Euchaeta antarctica. Prey size is, however, only one of several factors affecting prey encounter rate and the predators' ability and willingness to capture and ingest prey. The encounter rates of different size classes of prey are likely to be variable in the natural environment. In our study, the size of prey ingested by the adult Euchaeta females in the sea was highly variable, ranging from small Oncaea spp. to large Euchaeta spp. This was also the case in adult E. antarctica during summer in Gerlache Strait (Oresland 1991).

\section{Predation impact}

A small proportion of CVs and adult Euchaeta antarctica and E. biloba took a large portion of all prey. Accordingly, data from predation experiments and feeding analyses (including this one) based on few predators should be interpreted with care. The faecal pellets found in the guts close to the urosome contained a variable number of copepod prey items, even 
when one species dominated the diet as in CV E antarctica during winter. Accordingly rates of faecal pellet production alone cannot be used to predict feeding rates.

The occurrence of multiple prey was most pronounced in CV Euchaeta antarctica whose diet was dominated by small copepods. Yen (1991) reported higher predation rates by CIV relative to CV and adult $E$. antarctica when presented with small prey (Microcalanus). This indicates that stages CIV and younger may also have a high accurrence of multiple prey, perhaps resulting in an important predation impact on small copepods. So far, there exist no good simultaneously sampled abundance data for both small prey and Euchaeta for the South Georgia area. Hopkins et al. (1993) showed that the abundances of nauplii and small copepod species were seriously underestimated by plankton nets (plummet nets, $162 \mu \mathrm{m}$ mesh size) compared to estimates based on 301 bottle collections (filtered through a $30 \mu \mathrm{m}$ mesh).

Both predators with empty guts and those with many prey items were present in the same samples. High occurrences of Drepanopus forcipatus were found in stage CV Euchaeta antarctica even at stations where the abundance, as indicated by net hauls, was extremely low or indeed absent (Ward unpubl.). This, and the prey distributions among CVs (Fig. 2), indicate the possibility of prey patchiness and feeding on a scale less than that sampled by the net.

The mean number of prey per predator, the distribution of prey categories (Table 2), and the distribution of predators with different numbers of prey items in the gut (Figs. 1 \& 2) demonstrated no fundamental changes in feeding between seasons. This is in marked contrast to Yen (1991), who suggested that Euchaeta antarctica ceases feeding during winter in Gerlache Strait. In this context it is notable that E. antarctica reproduces during both summer and winter around South Georgia (Ward \& Robins 1987) as well as in Gerlache Strait (Øresland unpubl.).

\section{CONCLUSIONS}

The Euchaetidae had a variable diet consisting mainly of copepods. The high number of small prey in stage $\mathrm{V}$ Euchaeta antarctica indicate that young Euchaeta copepodite stages may be important predators on small copepods. The finding that few predators could in some cases take a large proportion of all prey items emphasises the variable nature of feeding and highlights the importance of adequate sampling scales and sample size in feeding studies. Gut content did not cease during winter, supporting the hypothesis that carnivorous feeding could be important during the Antarctic winter.

Acknowledgements. We thank the officers and crew of the RRS 'John Biscoe' and members of the British Antarctic Surveys Offshore Biological Programme for assistance in the field. We thank Thomas Hopkins who gave helpful comments on the manuscript. This work was financially supported by NFR (Sweden) under contract no. B-BU 8791-308.

\section{LITERATURE CITED}

Atkinson, A., Ward, P. (1988). Summer-winter differences in copepod distribution around South Georgia. Hydrobiologia 167/168: 325-334

Hopkins, T. L. (1985). Food web of an Antarctic midwater ecosystem. Mar. Biol. 89: 197-212

Hopkins, T. L. (1987). Midwater food web in McMurdo Sound, Ross Sea, Antarctica. Mar. Biol. 96: 93-106

Hopkins, T. L., Lancraft, T. M., Torres, J. J., Donnelly, J. (1993). Community structure and trophic ecology of zooplankton in the Scotia Sea marginal ice zone in winter (1988). Deep Sea Res. 40: 81-105

Hopkins, T. L., Torres, J. J. (1989). Midwater food web in the vicinity of a marginal ice zone in the western Weddell Sea. Deep Sea Res. 36: 543-560

North, A. W., Ward, P. (1990). The feeding ecology of larval fish in an Antarctic fjord, with emphasis on Champsocephalus gunnari. In: Kerry, K. R., Hempel, G. (eds.) Antarctic ecosystems. Ecological change and conservation. Springer Verlag, Berlin, p. 299-307

Øresland, V. (1990). Feeding and predation impact of the chaetognath Eukrohnia hamata in Gerlache Strait, Antarctic Peninsula. Mar. Ecol. Prog. Ser. 63: 201-209

Øresland, V. (1991). Feeding of the carnivorous copepod Euchaeta antarctica in Antarctic coastal and oceanic waters. Mar. Ecol. Prog. Ser. 78: 41-47

Park, T. (1978). Calanoid copepods belonging to the families Aetideidae and Euchaetidae from Antarctic and Subantarctic waters. In: Pawson, D. L. (ed.) Biology of the Antarctic seas 7, Antarctic Res. Ser. 27; 91-290

Roe, H. S. J., Shale, D. M. (1979). A new multiple rectangular midwater trawl (RMT $1+8$ ) and some modifications to the Institute of Oceanographic Science's RMT 1+8. Mar. Biol. 50: $283-288$

Ward, P. (1989). The distribution of zooplankton in an antarctic fjord at South Georgia during summer and winter. Antarctic Sci. 1: 141-150

Ward, P., Robins, D. B. (1987). The reproductive biology of Euchaeta antarctica Giesbrecht (Copepoda: Calanoida) at South Georgia. J. exp. mar. Biol. Ecol. 108: 127-145

Ward, P., Wood, A. G. (1988). The distribution of the Euchaetidae (Copepoda: Calanoida) around South Georgia. Polar Biol. 9: 45-52

Yen, J. (1991). Predatory feeding behavior of an Antarctic marine copepod, Euchaeta antarctica. Polar Res. 10: $443-442$

Manuscnpt first received: March 4, 1993

Revised version accepted: May 19, 1993 